\title{
Estimations of costs for dismantling, decommissioning and associated waste management of nuclear facilities, and associated impact on decision processes, functioning of markets and the distribution of responsibilities between generations
}

\author{
S. Lindskog ${ }^{1}$, A. Cato ${ }^{1} \&$ R. Sjöblom ${ }^{2}$ \\ ${ }^{1}$ The Swedish Nuclear Power Inspectorate, Sweden \\ ${ }^{2}$ Tekedo $A B$, Sweden
}

\begin{abstract}
The future dismantling, decommissioning and associated waste management of nuclear facilities constitute very substantial liabilities worldwide. Legislation and systems are in force in several countries to ensure that funds are available at the time when they are needed and that it is, according to the Polluters Pays Principle, the generations that benefit from the use of the nuclear facilities that also carry the financial burden.

This in turn constitutes a number of challenges which warrant proper attention, and which are dealt with in the present paper: how to carry the burden of financing, the need for securing the funds until the time when they are needed, and the need for precision in the cost calculations with regard to a number of factors. The latter includes the approach selected regarding fairness, in the allocation and distribution of the liabilities between generations, the requirements regarding the functioning of the system of finance (sufficient but not superfluous funding) and the quality warranted for the bases for various decisions needed (e.g. potential investment opportunities in new nuclear research reactors and/or nuclear power plant).

It is described how sufficiently precise cost calculations might be achieved using appropriate calculation methodologies in combination with radiological characterisation, technology selection and financial uncertainty analysis. Examples are given from authentic Nordic work on fuel cycle laboratory and pilot scale facilities.
\end{abstract}

Keywords: nuclear, decommissioning, decontamination, dismantling, radioactivity, liability, fund, cost calculation, estimate, environmental, legislation. 


\section{Preamble}

It is expected that perhaps hundreds of nuclear power reactors and other major nuclear facilities will be closed during the next few decades and thereby be awaiting dismantling and decommissioning. Such a closed facility typically represents a large negative monetary value with a negative cash-flow - perhaps even comparable in magnitude to that of the initial investment. The main reason for this is the presence of residues of radionuclides, which may well cause the cost for decommissioning to be a couple of orders of magnitude higher than would otherwise be the case.

Historically, responsible action in this regard has varied considerably between different types of nuclear facilities and geographic regions. In many cases, it has been left to Governments to finance remedial actions. A typical environmental project has had to compete with numerous other ones for funding and the result has typically been too little action at a late stage when the problems have already escalated.

There is a growing awareness internationally that appropriate and responsible decommissioning as well as waste management and disposal are fully integral parts of the utilization of nuclear energy. Consequently it is necessary that methods and techniques be developed and applied such that any effects on environment and health are small.

Hence, effective technical tools exist of many kinds for safe and efficient dismantling and decommissioning of various nuclear facilities. However, financial tools are also needed such that sufficient but not superfluous funding is made available at the time when it is needed.

The issues of appropriate and prudent funding as well as estimations of the funding needed are closely interlinked with a number of technical issues, thus making the full analysis of this system complex and difficult. There is a growing awareness of this internationally, e.g. through activities by IAEA, OECD/NEA and EU/COM as well as by many workers in the area. Systems for financing are being established in different countries, and experience is being gained on how to achieve the goal of adequate funding at the appropriate time for efficient and safe decommissioning of the various kinds of nuclear facilities.

The establishment of systems of finance requires that the needs and prerequisites are identified and established, and that difficulties are dealt with, feasible approaches found and effective methodologies developed. It is the purpose of the present paper to provide some detail and examples in this regard. It is largely a result of recent work [1] financed by the Swedish Nuclear Power Inspectorate and also the Nordic Nuclear Safety Research.

\section{Needs and prerequisites}

The polluter pays principle. The principle that it is the polluter that pays is now relatively generally accepted and established. In concordance, the IFRS (International Financial Reporting Standards) and the IAS (International Accounting Standards) that apply to stock companies in many countries have 
very strict rules on reliable and precise estimations of liabilities, and secure protection of the corresponding assets including monetary funds.

Identification of the polluter. The polluter is the one that is reaping the benefits of the operation of the facility in question. A corollary to this identification is that no burden should be placed on future generations, e.g. no encroachment should be allowed on the future consumption level due to any remedial actions, now or in the future.

The level of environmental quality after restoration. In theory, the liabilities should include dismantling and decommissioning of older nuclear power plats and other facilities as well as restoration of the land to initial conditions, i.e. green field conditions.

However, imposing such requirements within e.g. the EU area would undoubtedly be associated with considerable costs. Consequently, it has been discussed if brown field conditions might be acceptable. Such conditions would mean that some radioactive components, e.g. heavy structures, might be left indefinitely.

For the purpose of the present paper, the brown field conditions are discarded on grounds of it leaving responsibility of fairly easily accessible radioactive matter to future generations indefinitely, thus not complying with the polluter pays principle.

The link between the polluter and the restoration. It has also been discussed that nuclear site areas might be used for successive generations of nuclear facilities, and that green field conditions in this perspective might be required only at the end of a period of perhaps three to four nuclear generations. Such an approach might imply that there may up to 100-150 years between the first reaping of benefits and the final decommissioning of the land.

In the application of the polluter pays principle, it is important that the link between the allocation of assets and the full cost for the restoration be sufficiently strong. Extending the time frame over several human generations raises a number of questions including the one of the stability of the society. Moreover, restoration after just one generation is feasible. Consequently, the approach of successive use is also discarded from further consideration in the present paper.

Need for harmonization of requirements. There has been a successful deregulation of the energy market within the EU. This deregulation presupposes that the environmental requirements are equal for all producers, distributors and consumers. Otherwise some energy companies might be tempted to apply minimum or even inadequate environmental standards in order to gain a competitive edge.

Proper priority to liabilities. Business news media report that the median occupation time for managerial positions in industry may be only a few years. Since the environmental liabilities for nuclear facilities extend over decades it would be naïve to assume anything but that long term financing of environmental liabilities are likely to receive a lower priority as compared to e.g. short-term or quarterly profits. This may regard the level of ambition as well as the efforts put into the estimation of future costs. 
It was said above that the international rules on accounting imposes stringent requirements on proper priorities. This provides ample opportunities for various environmental and accounting authorities, auditors, investors and shareholders to gain insight and to oversee the management.

Systems of finance. In a number of countries and also within the EU, systems of finance have been established with requirements and oversight of the technical and financial planning processes. In such systems, cost calculations are reviewed by Government Authorities, thus affirming the process through e.g. Government decisions. The prerequisites for such processes include that there exists methodologies for reviews and assessments, independent competence and a knowledge base compiled through independent research. Systems of finance provide insight and assurance for the public, security for the facility owner and information to the tax authorities that the allocation of funds to cover future costs is not actually yet another way to defer or even avoid taxation.

A system like this also has to take into consideration that the financial accounts of the private enterprises that operate nuclear facilities are balanced against the budgets of the Governments that oversee them. It should also be recognized that in some cases, budgets of local municipalities are based heavily on revenues from nuclear power reactors. Thus, all so-called externalities (external effects) should be accounted for and enclosed within the funding system, including the various modes of distribution of responsibility between different stake-holders as well as between generations.

Funds controlled by the Government. It can be discussed whether funds and securities should be located at the industrial companies or be managed directly by a Government organization. The highest level of credibility is probably achieved with funds managed by impartial and competent Government officials. However, a general constraint in that the funds should be completely external and fully segregated from the accounts of companies as well as the regular accounts of the Government.

Quality of the planning process. It might be tempting to assume that the planning process including estimations of costs for decommissioning is similar to that of the erection of any new industrial plant. There are actually huge differences, and for a number of reasons. Moreover, the technical planning is closely interlinked with the cost calculations, since the selections of technologies to be applied depend strongly on their respective costs. The costs, in turn, depend strongly on the radiological situation in combination with various features of the design and operation, some of which might be difficult to identify and evaluate beforehand. Experience as well as documents issued by IAEA and other organizations unanimously show that a very thorough and qualified planning is required in order to achieve the level of precision needed for the requirements on the management of liabilities as well as on the functioning of a system of finance.

Robustness. As the link between the benefits of an operation and the restoration of its facilities and site is being stretched, possibilities may appear for various unplanned events, including accidents. It is highly desirable that a system of finance is robust with regard to such events. 
Changes in this regard might be triggered by some exogenous factors and stewardship might be lost. One example of this is the financing of decommissioning and dismantlement of the reactors in Chernobyl after the Ukraine had been separated from the former Soviet Union. Another example is the funding of decommissioning of the six reactors in the power plant "Bruno Leuschner" in Greifswald, which was accomplished by the transfer of the responsibility to the financial stronger parts of the Federative German Republic. It is envisaged that further similar changes may appear in the future, thus pinpointing the need to develop systems for adequate funding of future decommissioning.

\section{Suitable approaches and methodologies}

One major consideration in meeting the needs and considering the prerequisites above is the full realization of the multidisciplinary character of the area. Decommissioning is a discipline of its own in nuclear technology requiring special competence regarding the pertinent approaches in a decommissioning project as well as regarding the methodologies to be applied. For instance, radiological characterization and mapping for the purpose of decommissioning is usually very different from that warranted for day to day operation of the facility in question. It is important that the various skills and competences needed are represented, and that the dictatorship of the majority (usually nuclear engineers) is avoided, or at least balanced or mitigated. Most successful decommissioning projects have had heterogeneous groups with recurrent meetings, thus ensuring adequate responses to upcoming issues as well as propensity and flexibility to change approach when appropriate.

A key issue is the financial planning and review, and the associated combination of financial and technical competence. The ability to understand the prerequisites for the decommissioning of a facility is the key to prudent and appropriate estimates and thereby also to the availability of sufficient, but not superfluous, funding at the time when it is needed.

Focus is often placed on the tools (computer codes) applied for the estimation of the costs as well as on the budgetary classification used. The codes can provide very exact numbers if volumes and lengths of various entities are entered, and using the same budgetary classification among different projects simplifies comparison immensely.

However, uncritical use of such tools might be grossly misleading since various treacherous features may strongly influence the results. In the most extreme case the calculations will only be reproductions of calculations made on a similar facility at another time.

The cost of a project is closely associated with the radiological conditions, and thus codes that enable reliable results include parameters for degree of difficulty. This means that the outcome is not based entirely on per volume empirical parameters but also on difficulty factors that are established through empirical parameters in combination of assessments of the degrees of difficulty for the facility in question. 
The result can still not be trusted in general. The experience is that one has to go much further into the various possibilities available for improvement. This as well as actual calculations has been the topic of much of the research carried out by and on commission by the Swedish Nuclear Power Inspectorate, partly within the framework of a collaboration among the Nordic countries Denmark, Finland, Norway and Sweden [1]. Many of the findings have been compiled in an informal guidance document:

The cost estimation should be preceded with the following:

- A radiological survey tailored especially to meet the needs for cost calculations. Such a survey may include e.g. core sampling from a biological shield.

- $\quad$ Sampling design, including use of equipment for measuring

- Methodology selection based on the radiological survey. The selection should include alternative methodologies in case new information is appearing during the work

- Identification of potential cost risers as well as evaluation of the most important ones.

The work should include literature studies and plant visits of similar facilities and projects. Such communication might lead to improvement of the cost calculations through the introduction of actual costs for parts of facilities together with various scaling and weighing factors.

Much of the deviance between estimated costs and outcomes are actually related to various cost raisers. People are frequently anxious to present success stories at international conferences, and indeed, much can be learned from good examples. However, there are also a lot of lessons learned, but they are not as frequently reported on in the literature and on conferences. Therefore, in order to get input for proper planning and appropriate cost calculations, it is necessary to network with people in other facilities and learn from their experience.

It has been estimated in the above mentioned Nordic co-operation that by using the above approach and in reasonably uncomplicated cases, a precision in the cost estimate of $\pm 15 \%$ might be attained even for a research facility and at early stages of planning. It is notoriously difficult to estimate the costs for such facilities since they are built for a diversity of purposes, are frequently one of a kind, etc. The figure quoted should be used with great caution since there are numerous examples of much larger deviances between calculated and incurred costs.

The Nordic project has also included working through specific examples of old research facilities, one from each participating country. Although the countries are small, there is quite an abundance of old research and development facilities since these countries had very ambitious programmes for development of nuclear technology and nuclear power generation from the early fifties and at least a couple of decades onwards. 


\section{Conclusions}

Our studies - with special emphasis on the Nordic co-operative project mentioned above - have shown that there are systems available for capital budgeting for future costs. They can be used as platforms for including all costs and benefits in a Cost \& Benefit Analysis given the total and overall assets and liabilities of specific nuclear facilities. The demands from the society - even at an early stage - for comprehensive and complete estimations of the future costs for the residues from nuclear activities has necessitated the establishment of the current system, the scope of which can be widened to include essentially all costs to society from generation of electricity by means of nuclear power.

These systems can with fairy straightforward measures become fully integrated and compatible with the legislative demands on private enterprises regarding protection of assets to cover all liabilities for future environmental remediations as required in the IFRS (International Financial Reporting Standards) and the IAS (International Accounting Standards). Such a system requires that costs be estimated in a reliable way, which in turn presupposes development and use of good practice. The following features are essential and obtainable in this regard:

- Better estimates at an early stage of the expected live span of each individual site

- Better financial systems where funds are pinpointed for each facility/site.

Clearer and non-ambiguous rules for free release and alternative use of land

- $\quad$ Robust cost calculations such that any myopia of the present generation cannot give rise to any costs to the future generations.

- Development of methodologies for evaluation of environmental liabilities (including descriptions, demonstrations and calculations) in European Union and other international co-operation.

\section{Reference}

[1] Lindskog, S. et al. Summary of some recent work on financial planning for decommissioning of nuclear research facilities. To be published as SKI Report 2008:xx and available at www.ski.se. 